\title{
Nonengraftment Haploidentical Cellular Therapy for Hematologic Malignancies
}

\author{
John L. Reagan, Loren D. Fast, Eric S. Winer, Howard Safran, \\ James N. Butera, and Peter J. Quesenberry \\ Division of Hematology and Oncology, Rhode Island Hospital, The Warren Alpert Medical School, Providence, RI 02903, USA \\ Correspondence should be addressed to John L. Reagan, jreagan@lifespan.org
}

Received 14 September 2011; Accepted 24 November 2011

Academic Editor: Thomas Kickler

Copyright (c) 2012 John L. Reagan et al. This is an open access article distributed under the Creative Commons Attribution License, which permits unrestricted use, distribution, and reproduction in any medium, provided the original work is properly cited.

\begin{abstract}
Much of the therapeutic benefit of allogeneic transplant is by a graft versus tumor effect. Further data shows that transplant engraftment is not dependant on myeloablation, instead relying on quantitative competition between donor and host cells. In the clinical setting, engraftment by competition alone is not feasible due to the need for large numbers of infused cells. Instead, low-level host irradiation has proven to be an effective engraftment strategy that is stem cell toxic but not myeloablative. The above observations served as the foundation for clinical trials utilizing allogeneic matched and haploidentical peripheral blood stem cell infusions with minimal conditioning in patients with refractory malignancies. Although engraftment was transient or not apparent, there were compelling responses in a heavily pretreated patient population that appear to result from the breaking of tumor immune tolerance by the host through the actions of IFN $\gamma$, invariant NK T cells, CD8 T cells, NK cells, or antigen presenting cells.
\end{abstract}

\section{Introduction}

Allogeneic marrow transplantation exerts much of its therapeutic effect through graft killing of tumor cells. This was established in studies of the effect of donor lymphocyte infusions on relapsed chronic myelocytic leukemia (CML) in marrow transplant patients [1].

Initial insights on the presence of graft versus leukemia came from the work of Thomas and colleagues $[2,3]$, showing that leukemic relapses were lower in allogeneic transplant patients who had acute and chronic graft-versus-host disease (GVHD) as compared to those who did not develop these complications. Furthermore, patients with both acute and chronic GVHD had lower relapse rates than those with either acute or chronic GVHD alone $[4,5]$. There was an increased leukemic relapse rate in identical twin marrow transplants as compared to allogeneic transplants $[2,6]$. Tcell depletion from allogeneic marrow infusions decreased acute and chronic GVHD, but increased the rate of relapses. In a similar fashion, cyclosporine immunosuppression after allogeneic transplantation increased leukemic relapses, and discontinuation of the drug at the first sign of a relapse could induce a remission [7-9].
The most direct evidence of a cellular immune attack against leukemic cells was provided by Kolb and colleagues [1]. They demonstrated high rates of durable remissions in relapse CML with the simple infusion of donor lymphocytes. Donor lymphocyte responses after relapse from allogeneic transplant were also seen in patients with AML, ALL, MDS, polycythemia vera, lymphoma and myeloma [10, 11]. Thus cellular therapy in patients with a variety of marrow malignancies has been established and appears to be mediated by T lymphocytes although other cell types might also be involved.

\section{Origins of Nonmyeloablative Transplantation}

These studies suggested that cellular approaches without toxic myeloablative therapy might be effective treatment for many marrow malignancies. General dogma had been that myeloablative treatment was needed to open space so that marrow cells could engraft. However, Micklem et al., in 1968, demonstrated that engraftment into nonirradiated hosts was feasible, obtaining up to $8.5 \%$ T6T6 donor cells in CBA host marrow at 3 months after transplantation of 20 million 
marrow cells from normal T6T6 donors [12]. This work was extended by others [13-15].

The studies by Brecher and colleagues formed the basis for extensive studies in our laboratory on engraftment into nonmyeloablated mice, which in turn led to applications of nonmyeloablated transplantation in humans. Studying male $\mathrm{BALB} / \mathrm{c}$ marrow engrafted into female $\mathrm{BALB} / \mathrm{c}$ mice with no cytoreductive therapy, we determined that engraftment was essentially quantitative resulting from competition between infused cells and host cells. Evaluated mice which had received 5 consecutive intravenous injections of 40 million marrow cells showed continued engraftment in marrow at 21-25 months after transplant ranging from $15 \%$ to $42 \%$. Patterns of engraftment were similar for thymus and spleen [20]. Further studies showed that high numbers of cells given in one injection gave equal values to engraftment to the same number of cells divided over multiple injections [21-23]. Critical features of marrow engraftment were approached by determining total murine marrow cellularity and the observed engraftment percentages when 40 million marrow cells were infused (72 mice) and comparing those with theoretical outcomes [24]. Total cellularity in BALB/c mice was $530 \pm 20$ million cells, stable from 8 weeks to 1 year of age. Using this data, a theoretical model of infused marrow (40 million cells) replacing or adding to host marrow gave values of 7.5 and $7.0 \%$, respectively; the observed 8 -week engraftment of 40 million male BALB/c marrow cells into female hosts $(72$ mice) was $6.91 \pm 0.4 \%$. This indicated that syngeneic engraftment was determined solely by stem cell competition, not by "opening space". A summary of the above is depicted in List 1 .

\section{List 1: Engraftment Into Normal Untreated Mice.}

(i) High levels of chimerism seen in marrow, spleen, and thymus.

(ii) Chimerism persistent out to 2 years.

(iii) Chimerism was multilineage.

(iv) All donor cells appeared to have been engrafted. Final readouts were determined by competition between host and donor cells.

These data also indicated that so-called niches are not limiting as to engraftment, although there are clearly areas favoring specific differentiation pathways. Most "niche" studies need to be reconsidered since they have been carried using a dormant purified murine marrow stem cells, which do not appear to be representative of the true marrow longterm repopulating stem cell.

\section{The Role of Reduced Intensity Conditioning}

These data formed a base for engraftment into non-myeloablated mice. However, engraftment into non-myeloablated mice required large number of marrow cells, which would be difficult to obtain in a clinical setting. Accordingly, we investigated whether minimal myeloablation with low doses of irradiation would be an effective engraftment strategy [25]. In these studies, we demonstrated that exposure of $\mathrm{BALB} / \mathrm{c}$ mice to doses of irradiation that cause minimal myeloablation (50-100 cGy) gave high levels of donor chimerism, such that relatively small numbers of marrow cells (10-40 million) can give donor chimerism in the $40-100 \%$ range. These doses of irradiation turned out to be minimally myeloablative but quite stem cell toxic. Engraftable stem cells measured at 8 weeks after engraftment from mice exposed to $100 \mathrm{cGy}$ whole body irradiation were reduced to $8.6 \pm 3 \%$ of marrow from nonirradiated mice. At 6 months, the reduction was still present, $21 \pm 7 \%$ [26]. These data provided us with a stem cell toxic nonmyeloablative approach for therapeutic transplantation. Engraftment with reduced intensity conditioning is summarized in List 2.

\section{List 2: Minimal Myeloablation and Engraftment.}

(i) 50-100 cGy gives relatively high levels of engraftment with 10-40 million murine marrow cells.

(ii) These levels of irradiation are minimally myelotoxic with mild effects on blood counts.

(iii) These levels of irradiation are very stem cell toxic.

(iv) A stem cell toxic nonmyeloablative approach poses interesting therapeutic possibilities.

\section{Presence of Engraftment}

However, it was not clear if this would hold for allogeneic engraftment. Accordingly, we investigated engraftment into non or minimally myeloablated allogeneic mice. We felt that low-dose irradiation might avoid the cytokine storm which appeared to be involved in GVHD, and that relatively high levels of marrow cells might overcome rejection. However, we found that we could not obtain engraftment using 100 $300 \mathrm{cGy}$ and 40 million cells in H-2 mismatched B6.SJL to $\mathrm{BALB} / \mathrm{c}$ marrow transplants. Clearly, immune barriers existed.

We then tried antigen preexposure and costimulation blockade in this setting. Ten million B6.SJL spleen cells were infused into $\mathrm{BALB} / \mathrm{c}$ mice 10 days prior to transplantation, and anti-CD40 ligand antibody was given immediately prior to the spleen cell infusion and thereafter on days $-7,-3,0$, and +3 . On day 0,40 million B6.SJL whole marrow cells were infused into the $\mathrm{BALB} / \mathrm{c}$ hosts which had received $100 \mathrm{cGy}$ within 4 hours of marrow infusion. Stable multilineage chimerism at levels between $30-40 \%$ was achieved in the great majority of mice at $1.6 \mathrm{mg}$ anti-CD40 ligand monoclonal antibody per injection out to 64 weeks after transplantation [27]. There was no GVHD, and mice were tolerant to donor B6.SJL skin grafts.

We subsequently evaluated whether we could obtain significant marrow engraftment in this $\mathrm{H}-2$ mismatched model by first establishing microchimerism to set the stage for macrochimerism. We showed that establishment of microchimerism (0.5-3.8\%) with subsequent infusions of 40 million marrow cells on weeks 12,14 , and 16 or weeks $3,4,5$, and 6 with injections of anti-CD40 ligand antibody, but without irradiation or spleen cell injection, resulted in significant 
engraftment [28]. In the latter schedule, engraftment was $17.9 \pm 1.2 \%$ at 24 weeks. Thus, we could obtain significant engraftment with scheduled marrow cells and costimulator blockade. Giving the same number of total cells on day 0 did not result in significant chimerism. Therefore, a scheduling effect was critical for these results in mismatched allogeneic murine transplants. These results are different from the results in syngeneic transplants where scheduling appears to have no effect, rather total cell dose determines engraftment levels. These studies are summarized in List 3.

List 3: Minimal to No Myeloablation with Mismatched Allogeneic Marrow Transplantation.

(i) $100 \mathrm{cGy}$, spleen cell exposure and CD40 ligand antibody give significant chimerism with 40 million cells given in one injection.

(ii) A scheduled engraftment with 40 million cells given multiple times gives significant engraftment with only costimulator blockade.

\section{Clinical Trials}

These studies plus the evolving studies on the impact of donor lymphocyte infusions in clinical transplant set the stage for human trials using allogeneic or haploidentical peripheral blood infusions in patients with refractory cancers. Patients with refractory cancers were treated with $100 \mathrm{cGy}$ total body irradiation followed by infusion of nonmobilized apheresed allogeneic peripheral blood cells. Twenty-five patients were enrolled [29]. Transplants were with either HLA matched or 1/6 mismatched, one antigen mismatched family donors, or 4-6/6 antigen matched umbilical cord blood donor cells. Seven patients with solid tumors received a sibling transplant and 6 received a cord blood transplant; none achieved donor chimerism but 1 treated at the higher-dose level of $1 \times 10^{8} \mathrm{CD} 3+$ cells $/ \mathrm{kg}$ had a transient nodal response.

Twelve patients with hematologic malignancies were treated; eleven receiving sibling donor cells. Nine of these eleven achieved donor chimerism ranging from 5-100\%. In this group, there were four complete remissions and of these, three had 100\% chimerism. Two developed GVHD with one dying of liver GVHD and the other succumbing to disease relapse. One patient with AML and 100\% chimerism achieved a complete remission that required reinfusion of donor cells due to persistent pancytopenia. Interestingly, another patient with a large cell lymphoma and only transient $5 \%$ chimerism for one week developed a sustained complete remission for at least 42 months after transplantation. This particular patient was heavily pretreated with salvage chemotherapy and radiotherapy for relapsed disease following autologous transplantation. A similar remarkable response was seen without engraftment in a patient with CLL who witnessed a $75 \%$ decrease in lymphadenopathy, despite no evidence of chimerism.

In order to expand donor base, we next evaluated the safety and efficacy of haploidentical transplantation in a phase I/II nonimmunosuppressive nonmyeloablative setting
[16]. A total of 41 patients with relapsed refractory cancers received $100 \mathrm{cGy}$ total body irradiation along with an infusion of $1 \times 10^{6}$ to $2 \times 10^{8} \mathrm{CD} 3+$ cells per kilogram. Twenty nine patients received the highest dose of $2 \times 10^{8}$ cells $/ \mathrm{Kg}$. A post-infusional syndrome termed "haploimmunostorm" was seen at the two highest cell levels. This consisted of fever with a median onset of 14 hours after cell infusion and malaise, liver function test alterations, morbilliform rash, and diarrhea to varying degrees. Skin biopsies were negative for GVHD. This syndrome rapidly responded to steroid administration and was probably a variant of cytokine storm.

In all, there were 26 patients with hematologic malignancies with 14 responses, 7 of which were major. Two of six patients with lymphoma remained free of disease at 76 and 82 months, respectively. There were 5 durable complete responses and 4 partial responses in 13 patients with AML. All responses occurred outside the donor chimerism with sensitivity of $1-5 \%$ in the chimerism determinations. There were no responses with the solid tumor patients, and two patients who converted to total chimerism died, one of GVHD. Altogether, these results indicated that there was significant antitumor activity in the setting of rejection of infused marrow cells, some of which were clinically significant. Presently, the mechanisms underlying this are unclear, but we favor a breaking of host tolerance to tumor cells. These results are summarized in List 4.

\section{List 4: Allogeneic and Haploidentical Cellular Therapy of Hematologic Malignancies.}

(i) HLA-matched engraftment in nonmyeloablated setting showed tumor responses associated with chimerism.

(ii) Haploidentical infusions in nonmyeloablated setting caused responses in lymphoma and AML patients without chimerism.

Clearly, nonengraftment (at least maxi-engraftment) presents a potentially new direction in therapy of refractory hematologic malignancies. An interesting study from China [17] in elderly patients indicated that adding haploidentical cell infusions to chemotherapy markedly improved results with no GVHD, but with persistent donor microchimerism. Prolonged survival in patients who do not achieve engraftment has been reported elsewhere in patients with acute lymphocytic leukemia, non-Hodgkin lymphoma, Hodgkin lymphoma, myelodysplastic syndrome, and multiple myeloma $[18,19]$.

These results summarized in Table 1 suggest that studies of hematologic malignancies in which marrow rejection is the goal are indicated to more fully evaluate both clinical efficacy and underlying mechanism.

\section{Proposed Mechanism of Action}

The underlying mechanism of cellular therapy efficacy is only recently coming to light and is thought to include everything from the growth factors employed for cell collection to the actual composition of the cells themselves. Clearly $\mathrm{T}$ cells 
TABLE 1: Summary of nonengraftment cellular therapy results.

\begin{tabular}{|c|c|c|c|c|}
\hline Author & Number of patients & Conditioning regimen & $\begin{array}{l}\text { Number of CD3 cells } \\
\text { infused }\end{array}$ & $\begin{array}{l}\text { Response rate } \\
(\mathrm{CR} / \mathrm{PR})\end{array}$ \\
\hline Colvin et al. [16] & 19 patients (AML/NHL only) & 100 cGy TBI & $1 \times 10^{6}-2 \times 10^{8} / \mathrm{kg}$ & $37 \%(26 \% / 11 \%)$ \\
\hline Guo et al. [17] & 30 patients (AML) & $\begin{array}{l}\text { Mitoxantrone } 8-10 \mathrm{mg} / \mathrm{m}^{2} \\
(3 \text { days) and cytarabine } \\
150 \mathrm{mg} / \mathrm{m}^{2} \text { (7 days) }\end{array}$ & $0.5-2.6 \times 10^{8} / \mathrm{kg}$ & $80 \%(80 \% / \mathrm{NR})$ \\
\hline $\begin{array}{l}\text { *O’Donnell et al. } \\
{[18]}\end{array}$ & 4 patients (ALL, MDS) & $\begin{array}{l}\text { Fludarabine } 30 \mathrm{mg} / \mathrm{m}^{2} \text {, } \\
200 \mathrm{cGy} \text { TBI, Post } \\
\text { transplant } \pm \text { Pretransplant } \\
\text { cyclophosphamide }\end{array}$ & $2.6-3.8 \times 10^{7} / \mathrm{kg}$ & $75 \%(75 \% / 0 \%)$ \\
\hline * Dey et al. [19] & $\begin{array}{l}22 \text { patients (NHL, HL, Multiple } \\
\text { Myeloma) }\end{array}$ & $\begin{array}{l}\text { Cyclophosphamide } \\
50 \mathrm{mg} / \mathrm{kg} \text { (3-4 days), ATG } \\
15-30 \mathrm{mg} / \mathrm{kg} \text { ( } 3-4 \text { days), } \\
\text { and anti-CD } 2 \text { monoclonal } \\
\text { antibody }\end{array}$ & $1 \times 10^{7}-2.98 \times 10^{8} / \mathrm{kg}$ & $41 \%(18 \% / 22 \%)$ \\
\hline
\end{tabular}

* Only patients who did not engraft in this study are included in the results. AML= acute myeloid leukemia, NHL= non-Hodgkins lymphoma, MDS= myelodysplastic syndrome, $\mathrm{ALL}=$ acute lymphocytic leukemia, $\mathrm{HL}=$ Hodgkins lymphoma.

are involved in this process; however, neither the bystander killing effect nor the $\mathrm{T}$ cell receptor cross reactivity to allogeneic antigens with tumor antigens is thought to play a role. Central to the development of a graft versus leukemia or host versus leukemia response is the underlying regulation between the development of a $\mathrm{T}_{\mathrm{H}} 1$ response and a graft or host versus tumor effect (and with it the potential for acute or chronic GVHD) and a $\mathrm{T}_{\mathrm{H}} 2$ response that allows for tolerance of the graft and prevents GVHD. Clinical trials suggest that an initial engraftment of donor cells followed by the host rejection of this engraftment is essential to developing a host versus tumor response. Based on this concept, Sykes and colleagues developed a mixed chimeric bone marrow murine model to more fully understand the mechanism of this response. The mixed chimera developed represents the initial infusion and partial engraftment of haploidentical cells. They are then able to model the rejection of these haploidentical cells through the infusion of recipient murine leukocytes (RLI). RLI infusion then induces a host versus graft (HVG) reaction that results in an antitumor response by the host's immune system to malignancies present within the host which they have been able to further characterize. This response requires a complex interaction between interferon$\gamma($ IFN- $\gamma$ ), CD8 T cells, invariant NK-T cells (iNKT), NK cells, and antigen presenting cells.

Early work by this group first disclosed the importance of IFN- $\gamma$ in the development of an antitumor response. They further determined that IFN- $\gamma$ derived from the recipient was essential for the development of an antitumor response [30]. Overall, a robust cytokine response was seen clinically when mixed chimerism is lost. Although many other cytokines are involved in this response, experiments have shown that IFN- $\gamma$ generation was crucial for an antitumor response. IFN- $\gamma$ is also important in the allogeneic transplantation graft versus leukemia effect [31]. Later experiments determined that IFN- $\gamma$ production initially is through RLI CD8+ T cells by leukocytes present within the RLI fraction as well as non RLI recipient leukocytes. The presence of RLI
CD8+ T cells and non RLI recipient CD4+ cells is crucial for the development of antitumor responses to RLI [32]. Also involved in the anti-tumor response are recipient iNK-T cells with the anti-tumor effects of these cells distinct from RLI CD8+ T cells. Following RLI, iNK-T cells become activated and in turn activate both recipient NK cells and dendritic cells [33]. The end theoretical result is the immune activation and subsequent breaking of host tolerance to tumor.

In addition to the cells themselves, the initial collection of cells for infusion and methods therein may play a role. For example, G-CSF has been shown to promote $\mathrm{T}_{\mathrm{H}} 2$ differentiation and $\mathrm{T}$ regulatory cell proliferation, while also expanding the pool of immature antigen presenting cells. All of these measures help prevent the development of GVHD, while not inhibiting the cytolytic $\mathrm{T}$ cell graft versus tumor effect. A further increase in GVT is seen when G-CSF is pegylated, which leads to activation of invariant NK cells. These cells are thought to play a role in the development of cytotoxic response through cytokine release that leads to further recruitment of NK cells and CD8+ CTLs [34]. Other cell types such as CD4+/CD25+ T regulatory cells (T-regs) have been shown to play a role in the donor and recipient cell interactions in haploidentical transplant where engraftment occurs $[35,36]$. Tregs appear to have a role in host tolerance and allow for an increase in engraftment with a decrease in GvHD. The role Tregs have in the nonengraftment setting is still unclear.

\section{Conclusions}

As outlined above, cell infusional treatment of leukemia and lymphoma is not completely dependent on graft versus tumor/leukemia effect. Rather, rejection of the graft itself appears to reeducate the host's immune system to recognize the tumor, thereby creating a host versus tumor effect. This method is not without its side effects in the form of a cytokine storm involving IFN- $\gamma$ but does bypass the morbidity and mortality that develop from graft versus host disease. 
An additional advantage of non-engraftment haploidentical transplantation over allogeneic transplantation is the availability of donors. Family members are readily identified as potential donors making this a readily available treatment modality. The overall keys to the future of nonengraftment haploidentical transplantation reside in better understanding of the degree of chimerism, if any, necessary for a reaction as well as the timing and role of host effector cell stimulation. The potential result is the ability to harness the host's immune system in order to provide an effective therapeutic modality to eradicate malignancy. Future studies should help decipher the underlying interaction that occurs between host and donor cells. Key questions that remain are the amount and type of conditioning regimen as well as the degree of antigenic mismatch required to stimulate a host versus tumor response in vitro and in vivo. Potential further clinical trials could focus on decreasing or eliminating radiation or chemotherapy conditioning in addition to examining the effects of complete HLA mismatch in order to further remove any chance of engraftment and with it GvHD development. Moreover, future trials may also explore the role of multiple cellular infusions spaced out in a treatment plan to possibly elicit a more robust response.

\section{Conflict of Interests}

The authors have no conflict of interests to declare.

\section{References}

[1] H. J. Kolb, J. Mittermuller, C. Clemm et al., "Donor leukocyte transfusions for treatment of recurrent chronic myelogenous leukemia in marrow transplant patients," Blood, vol. 76, no. 12, pp. 2462-2465, 1990.

[2] A. Fefer, M. A. Cheever, E. D. Thomas et al., "Bone marrow transplantation for refractory acute leukemia in 34 patients with identical twins," Blood, vol. 57, no. 3, pp. 421-430, 1981.

[3] P. L. Weiden, K. M. Sullivan, N. Flournoy, R. Storb, and E. D. Thomas, "Antileukemic effect of chronic graft-versus-host disease. Contribution to improved survival after allogeneic marrow transplantation," The New England Journal of Medicine, vol. 304, no. 25, pp. 1529-1533, 1981.

[4] G. C. de Gast, P. G. Beatty, D. Amos et al., "Transfusion effect on graft-versus-host disease and leukemic relapse in HLAmatched bone marrow transplantation," Transplantation Proceedings, vol. 19, no. 1, p. 2700, 1987.

[5] J. A. Sosman and P. M. Sondel, "The graft versus leukemia effect: possible mechanisms and clinical significance to the biologic therapy of leukemia," Bone Marrow Transplantation, vol. 7, supplement 1, pp. 33-37, 1991.

[6] R. P. Gale and R. E. Champlin, "How does bone-marrow transplantation cure leukaemia?” The Lancet, vol. 2, no. 8393, pp. 28-30, 1984.

[7] C. S. Higano, M. Brixey, E. M. Bryant et al., "Durable complete remission of acute nonlymphocytic leukemia associated with discontinuation of immunosuppression following relapse after allogeneic bone marrow transplantation. A case report of a probable graft-versus-leukemia effect," Transplantation, vol. 50, no. 1, pp. 175-177, 1990.
[8] R. H. Collins Jr., Z. R. Rogers, M. Bennett, V. Kumar, A. Nikein, and J. W. Fay, "Hematologic relapse of chronic myelogenous leukemia following allogeneic bone marrow transplantation: apparent graft-versus-leukemia effect following abrupt discontinuation of immunosuppression," Bone Marrow Transplantation, vol. 10, no. 4, pp. 391-395, 1992.

[9] L. F. Odom, C. S. August, J. H. Githens et al., "Remission of relapsed leukaemia during a graft-versus-host reaction. A "graft-versus-leukaemia reaction" in man?" The Lancet, vol. 2, no. 8089, pp. 537-540, 1978.

[10] H. J. Kolb, A. Schattenberg, J. M. Goldman et al., "Graft-versus-leukemia effect of donor lymphocyte transfusions in marrow grafted patients," Blood, vol. 86, no. 5, pp. 2041-2050, 1995.

[11] C. K. Lee, M. de Magalhaes-Silverman, R. J. Hohl et al., "Prophylactic $\mathrm{T}$ cell infusion after $\mathrm{T}$ cell-depleted bone marrow transplantation in patients with refractory lymphoma," Bone Marrow Transplantation, vol. 29, no. 7, pp. 615-620, 2002.

[12] H. S. Micklem, C. M. Clarke, E. P. Evans, and C. E. Ford, "Fate of chromosome-marked mouse bone marrow cells tranfused into normal syngeneic recipients," Transplantation, vol. 6, no. 2, pp. 299-302, 1968.

[13] A. Takada, Y. Takada, and J. L. Ambrus, "Proliferation of donor spleen and bone-marrow cells in the spleens and bone marrows of unirradiated and irradiated adult mice," Proceedings of the Society for Experimental Biology and Medicine, vol. 136, no. 1, pp. 222-226, 1971.

[14] G. Brecher, J. D. Ansell, H. S. Micklem, J. H. Tjio, and E. P. Cronkite, "Special proliferative sites are not needed for seeding and proliferation of transfused bone marrow cells in normal syngeneic mice," Proceedings of the National Academy of Sciences of the United States of America, vol. 79, no. 16, pp. 5085-5087, 1982.

[15] D. F. Saxe, S. S. Boggs, and D. R. Boggs, "Transplantation of chromosomally marked syngeneic marrow cells into mice not subjected to hematopoietic stem cell depletion," Experimental Hematology, vol. 12, no. 4, pp. 277-283, 1984.

[16] G. A. Colvin, D. Berz, M. Ramanathan et al., "Nonengraftment haploidentical cellular immunotherapy for refractory malignancies: tumor responses without chimerism," Biology of Blood and Marrow Transplantation, vol. 15, no. 4, pp. 421-431, 2009.

[17] M. Guo, K. X. Hu, C. L. Yu et al., "Infusion of HLA-mismatched peripheral blood stem cells improves the outcome of chemotherapy for acute myeloid leukemia in elderly patients," Blood, vol. 117, no. 3, pp. 936-941, 2011.

[18] P. V. O’Donnell, L. Luznik, R. J. Jones et al., “Nonmyeloablative bone marrow transplantation from partially HLA-mismatched related donors using posttransplantation cyclophosphamide," Biology of Blood and Marrow Transplantation, vol. 8, no. 7, pp. 377-386, 2002.

[19] B. R. Dey, S. McAfee, C. Colby et al., "Anti-tumour response despite loss of donor chimaerism in patients treated with nonmyeloablative conditioning and allogeneic stem cell transplantation," British Journal of Haematology, vol. 128, no. 3, pp. 351-359, 2005.

[20] F. M. Stewart, R. B. Crittenden, P. A. Lowry, S. P. White, and P. J. Quesenberry, "Long-term engraftment of normal and post5-fluorouracil murine marrow into normal nonmyeloablated mice," Blood, vol. 81, no. 10, pp. 2566-2571, 1993.

[21] H. S. Ramshaw, S. S. Rao, R. B. Crittenden, S. O. Peters, H. U. Weier, and P. J. Quesenberry, "Engraftment of bone marrow cells into normal unprepared hosts: effects of 5-fluorouracil and cell cycle status," Blood, vol. 86, no. 3, pp. 924-929, 1995. 
[22] H. S. Ramshaw, R. B. Crittenden, M. Dooner, S. O. Peters, S. S. Rao, and P. J. Quesenberry, "High levels of engraftment with a single infusion of bone marrow cells into normal unprepared mice," Biology of Blood and Marrow Transplantation, vol. 1, no. 2, pp. 74-80, 1995.

[23] S. S. Rao, S. O. Peters, R. B. Crittenden, F. M. Stewart, H. S. Ramshaw, and P. J. Quesenberry, "Stem cell transplantation in the normal nonmyeloblasted host: relationship between cell dose, schedule, and engraftment," Experimental Hematology, vol. 25, no. 2, pp. 114-121, 1997.

[24] G. A. Colvin, J. F. Lambert, M. Abedi et al., "Murine marrow cellularity and the concept of stem cell competition: geographic and quantitative determinants in stem cell biology," Leukemia, vol. 18, no. 3, pp. 575-583, 2004.

[25] F. M. Stewart, S. Zhong, J. Wuu, C. C. Hsieh, S. K. Nilsson, and P. J. Quesenberry, "Lymphohematopoietic engraftment in minimally myeloablated hosts," Blood, vol. 91, no. 10, pp. 3681-3687, 1998.

[26] F. M. Stewart, S. Zhong, J. F. Lambert et al., "Host marrow stem cell potential and engraftability at varying times after low-dose whole-body irradiation," Blood, vol. 98, no. 4, pp. 1246-1251, 2001.

[27] P. J. Quesenberry, S. Zhong, H. Wang, and M. Stewart, "Allogeneic chimerism with low-dose irradiation, antigen presensitization, and costimulator blockade in $\mathrm{H}-2$ mismatched mice," Blood, vol. 97, no. 2, pp. 557-564, 2001.

[28] J. F. Lambert, G. A. Colvin, S. Zhong et al., "H2-mismatched transplantation with repetitive cell infusions and CD40 ligand antibody infusions without myeloablation," British Journal of Haematology, vol. 119, no. 1, pp. 155-163, 2002.

[29] K. K. Ballen, P. S. Becker, R. V. B. Emmons et al., "Low-dose total body irradiation followed by allogeneic lymphocyte infusion may induce remission in patients with refractory hematologic malignancy," Blood, vol. 100, no. 2, pp. 442-450, 2002.

[30] M. T. Rubio, Y. M. Kim, T. Sachs, M. Mapara, G. Zhao, and M. Sykes, "Antitumor effect of donor marrow graft rejection induced by recipient leukocyte infusions in mixed chimeras prepared with nonmyeloablative conditioning: critical role for recipient-derived IFN- $\gamma$," Blood, vol. 102, no. 6, pp. 23002307, 2003.

[31] Y. Yang, H. Wang, H. Yu et al., "IFN- $\gamma$ promotes graft-versusleukemia effects without directly interacting with leukemia cells in mice after allogeneic hematopoietic cell transplantation," Blood, vol. 118, no. 13, pp. 3721-3724, 2011.

[32] M. T. Rubio, T. I. Saito, K. Kattleman, G. Zhao, J. Buchli, and M. Sykes, "Mechanisms of the antitumor responses and hostversus-graft reactions induced by recipient leukocyte infusions in mixed chimeras prepared with nonmyeloablative conditioning: a critical role for recipient $\mathrm{CD} 4^{+} \mathrm{T}$ cells and recipient leukocyte infusion-derived IFN-gamma-producing $\mathrm{CD}^{+} \mathrm{T}$ cells," Journal of Immunology, vol. 175, no. 2, pp. 665-676, 2005.

[33] T. I. Saito, H. W. Li, and M. Sykes, "Invariant NKT cells are required for antitumor responses induced by host-versus-graft responses," Journal of Immunology, vol. 185, no. 4, pp. 20992105, 2010.

[34] E. S. Morris, K. P. A. MacDonald, and G. R. Hill, "Stem cell mobilization with G-CSF analogs: a rational approach to separate GVHD and GVL?" Blood, vol. 107, no. 9, pp. 34303435, 2006.

[35] M. di Ianni, F. Falzetti, A. Carotti et al., "Tregs prevent GVHD and promote immune reconstitution in HLA-haploidentical transplantation,” Blood, vol. 117, no. 14, pp. 3921-3928, 2011.
[36] J. Yu, X. Ren, F. Yan et al., "Alloreactive natural killer cells promote haploidentical hematopoietic stem cell transplantation by expansion of recipient-derived $\mathrm{CD} 4^{+} \mathrm{CD} 25^{+}$regulatory $\mathrm{T}$ cells," Transplant International, vol. 24, no. 2, pp. 201-212, 2011. 


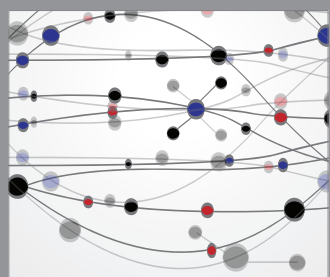

The Scientific World Journal
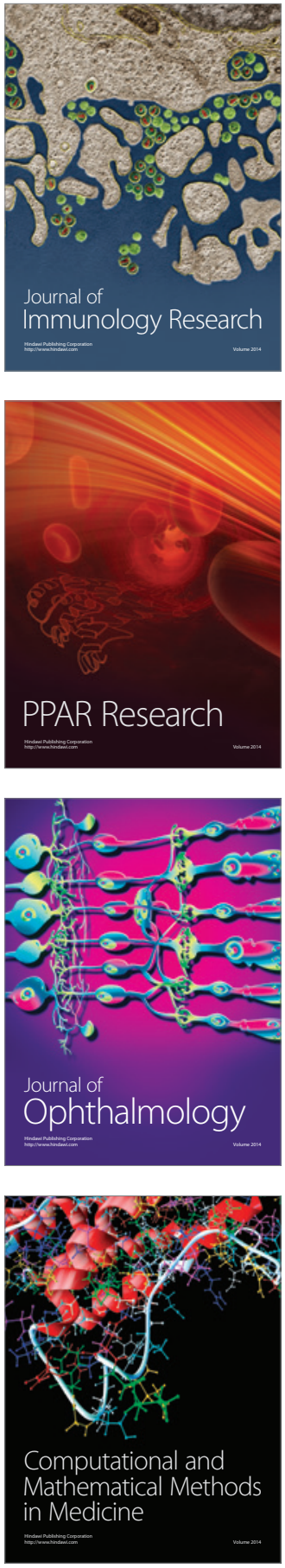

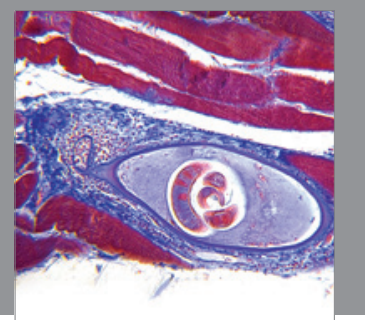

Gastroenterology

Research and Practice
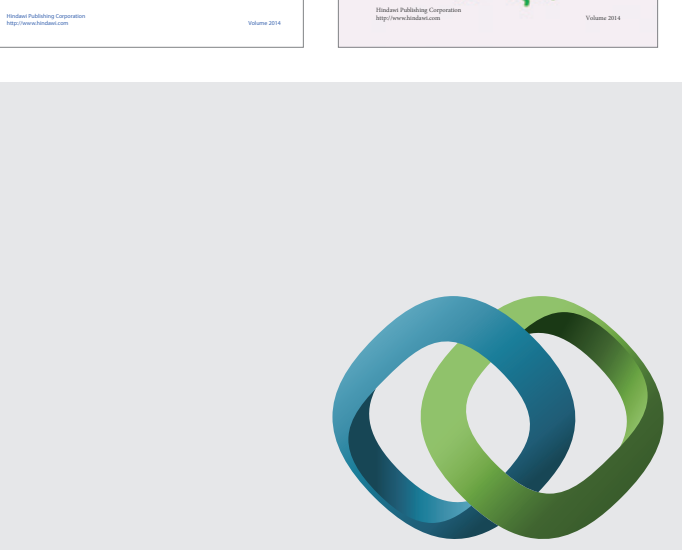

\section{Hindawi}

Submit your manuscripts at

http://www.hindawi.com
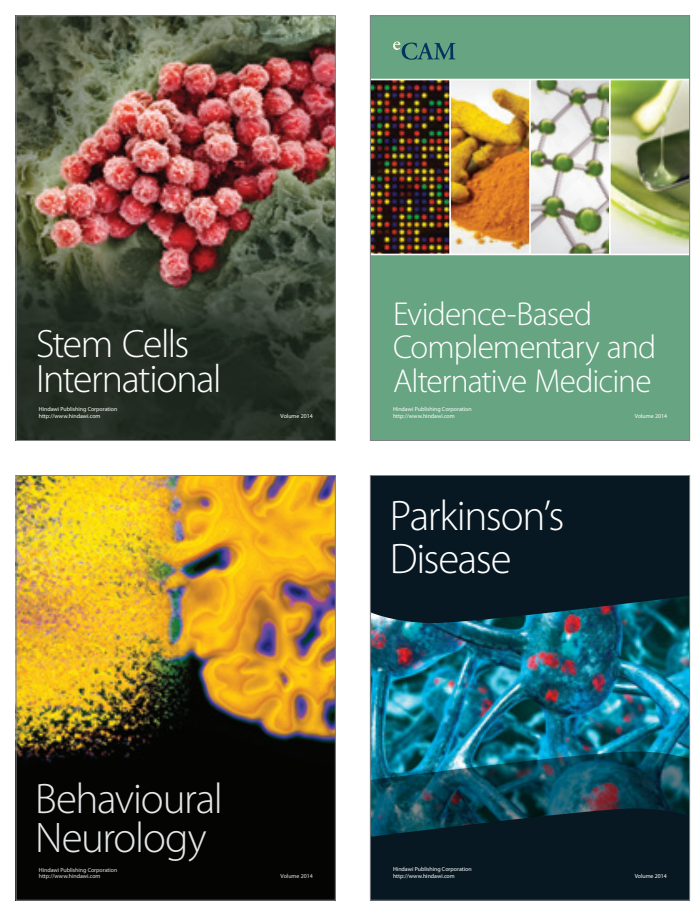

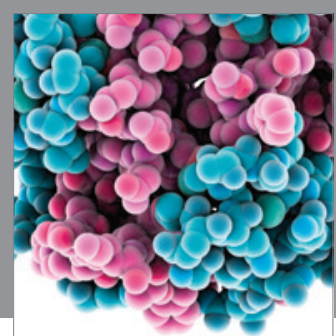

Journal of
Diabetes Research

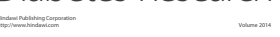

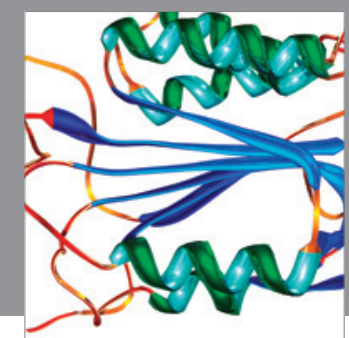

Disease Markers
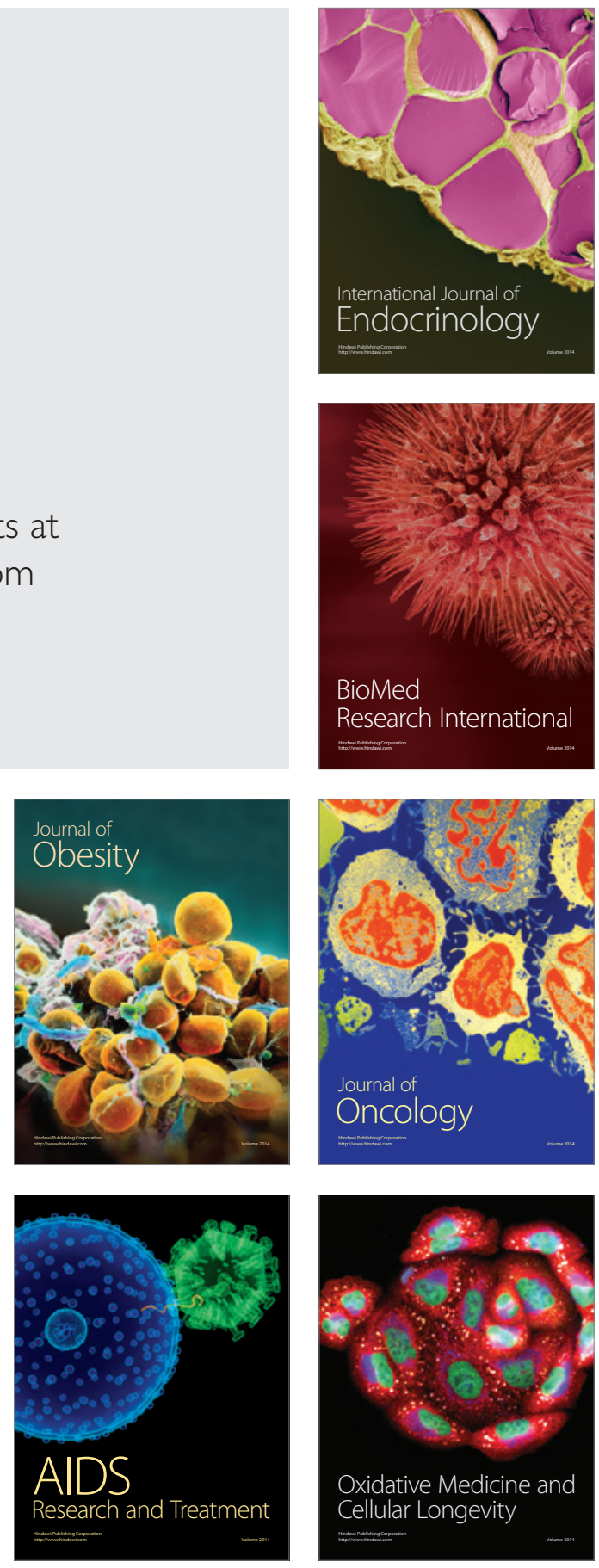